\title{
Unis geschlossen - Lehre digital: Mit unirad!
}

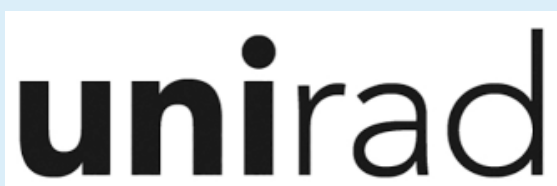

Lehrmodule für Studierende

In der Corona-Krise bleiben die Hörsäle geschlossen, Lehrende sind stark in die medizinische Betreuung eingebunden. Bedarf an medizinischer Ausbildung besteht dennoch - oder gerade jetzt! Die DRG bietet mit der interaktiven Lehr- und Lernplattform unirad eine Möglichkeit, Studierenden Wissen digital zu vermitteln.

In unirad stehen zwei umfangreiche Kurse für die studentische Lehre zur Verfügung, die von mehreren universitätsmedizinischen Standorten zusammen erstellt wurden. Es werden Fallsammlungen aus den Bereichen Thorax, Abdomen, Muskuloskelettal- und Neuroradiologie in jeweils einem Basiskurs und einem Aufbaukurs angeboten. Unter Hochdruck arbeiten Expertinnen und Experten gegenwärtig daran, das Port-

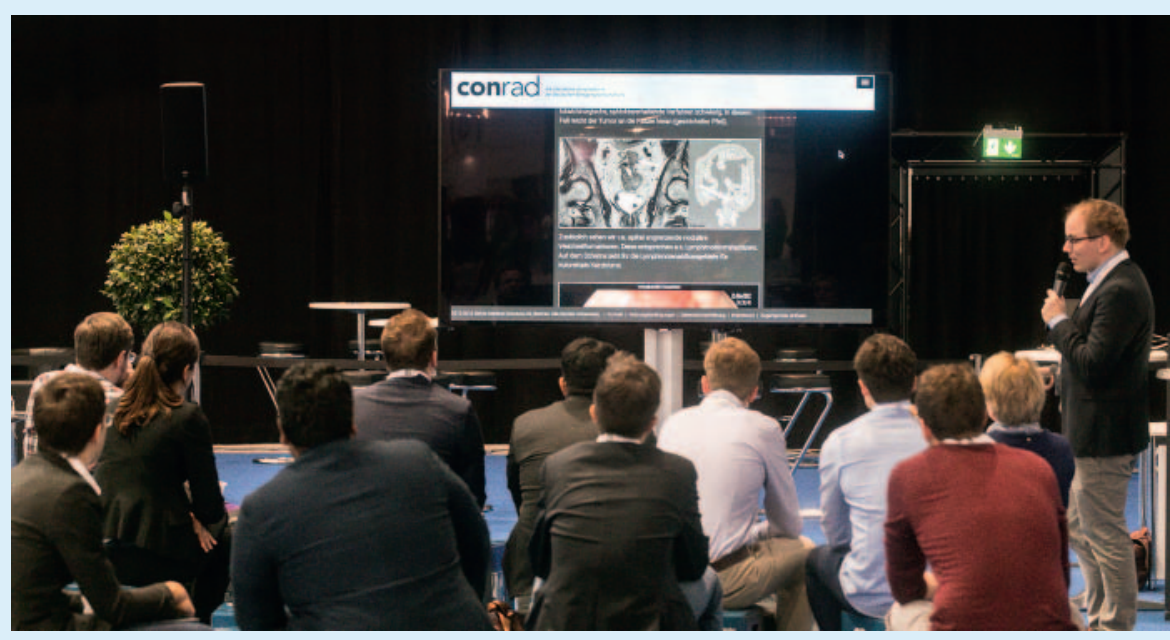

unirad auf dem 100. RöKo, (c DRG/Thomas Rafalzyk

folio um aktuelle Fälle und Informationen aus dem Themenbereich COVID-19 zu ergänzen.

der DRG-Geschäftsstelle ist Herr Olaf Goldschmidt (Telefon: 030/916 070-47; E-Mail: goldschmidt@drg.de).

Die aufwändig didaktisch aufbereiteten Lehrmaterialien können nun von allen Uni-

Weitere Informationen finden Sie unter: www.drg.de > Aktuelles

versitätsstandorten in der Lehre eingesetzt werden. Der Ansprechpartner für unirad in 